\title{
DAMPAK DIVIDEND YIELD DAN PRICE EARNING RATIO TERHADAP REAKSI INVESTOR PADA PERUSAHAAN MANUFAKTUR DI INDONESIA
}

\author{
Vella Nurhaliza ${ }^{1)}$, Irdha Yusra ${ }^{2}$ \\ ${ }^{1,2)}$ Jurusan Manajemen, Sekolah Tinggi Ilmu Ekonomi KBP \\ Email: vella.management22@gmail.com \\ Email Pembimbing: irdhayusra@akbpstie.ac.id
}

\begin{abstract}
This study purposes to test the effect of the dividend yield $(D Y)$ and price earnings ratio (PER) to the reaction of investors (proxy using the stock return). The population used in this study is of Manufacturing Subsector Food and Beverage listed on the Indonesia Stock Exchange (BEI) during the period 2011 to 2015 as many as 14 companies. From this, the sample was taken comprising 7 companies. This took a period from period 2011-2015, using purposive sampling method.

The Data analysis technique used is multiple linear regression using eviews program. From the results of tests performed showed that the dividend yield was statistically not significant effect return, as indicated by the probability of $>0.05$ is 0.5916 . Be diffirent with price earnings ratio is statistically significant effect on return, as indicated by the probability of $<0.05$ is 0.0164 .
\end{abstract}

Keywords: Dividend Yield, Price Earning Ratio, and Return.

\section{A. Pendahuluan}

Perusahaan manufaktur berasal dari kata manufacture yang merupakan menciptakan dengan tangan (manual) maupun mesin sehingga menghasilkan barang. (Heizer, dkk. 2005). Dalam menjalankan fungsi ekonomi orang perorangan atau lembaga melakukan bentuk penanaman modal (investasi). Tujuan investor dalam berinvestasi adalah memaksimalkan return, tanpa melupakan faktor risiko investasi yang harus dihadapinya. Return merupakan salah satu faktor yang memotivasi investor berinvestasi dan juga merupakan imbalan atas keberanian investor menanggung risiko atas investasi yang dilakukannya (Tandelilin, 2010). Reaksi investor dapat diukur dengan menggunakan return. 
Bentuk pendapatan yang diterima dari investasi saham dapat berupa dividend atau capital gain. Dividend Yield merupakan salah satu indikator penilaian kebijakan dividend yang dgunakan para investor untuk mengivestasikan dana yang mereka miliki. Informasi mengenai prediksi kemampuan perusahaan dalam menghasilkan laba dimasa yang akan datang para investor menggunakanm price earning ratio. Penggunaan price earning ratio dalam perusahaan memberikan peranan penting dalam mengetahui pertumbuhan dividen perusahaan dimasa mendatang dan memiliki emampuan dalam menghitung return saham secara sectional.

Masalah yang sering dihadapi investor dipasar modal adalah memilih perusahaan yang tepatuntuk melakukan investasi agar diperoleh investasi dengan harga yang wajar dan mencerminkan investasi yang pontensial. Hal ini dikarenakan adanya permasalahan yang dihadapi pertumbuhan industri manufaktur dimasa yang akan datang yaitu gencatan ekonomi makro dan mikro, diantaranya mulai apresiasi rupiah, naiknya upah buruh, tingginya biaya logistik, hingga sulitnya mengakses pinjaman bank serta tidak stabilnya tingkat return saham perusahaan di Indonesia. Hal ini dapat dilihat dari perkembangan perusahaan manufaktur subsektor makanan dan minuman yang terdaftar di Bursa Efek Indonesia periode 2013-2015 yang mengalami fluktuasi. Berdasarkan data perusahaan di BEI diketahui bahwa bahwa dividend yield dan price earning ratio pada tahun 2014 dan 2015 menunjukkan kondisi yang konsisten dengan return saham pada perusahaan manufaktur subsekstor makanan dan minuman. Berbeda dengan dividend yield dan price earning ratio pada tahun 2013 menunjukan kondisi yang tidak konsisten dengan return saham pada perusahaan manufaktur subsekstor makanan dan minuman Hal ini berarti investor tidak selalu merespon atau bereaksi terhadap tinggi atau rendahnya nilai dividend yield dan price earning ratio pada perusahaan manufaktur.

Beberapa penelitian terdahulu tentang dividend yield dan price earning ratio terhadap return saham adalah penelitian yang dilakukan oleh Wagiri (2013), Fernandus (2015), Meythi dan Mathilda (2012), dan Jatmiko (2015). Wagiri (2013) Dia menemukan bahwa dividend yield berpengaruh negatif dan tidak signifikan terhadap harga saham. Hasil penelitian ini sejalan dengan penelitian yang dilakukan oleh Fernandus (2015) Dia menyatakan bahwa dividend yield tidak berpengaruh positif terhadap harga saham. Meythi dan Mathilda (2012) menyatakan bahwa secara parsial price earning ratio memiliki pengaruh negatif dan tidak signifikan terhadap return saham. Jatmiko (2015), Dia mengatakan bahwa price earninng ratio berpengaruh negatif terhadap return.

Namun berbeda pada penelitian yang telah dilakukan oleh Margaretha dan Irma (2008) dalam penelitiannya mengunakan variabel stock return menyatakan bahwa dividend yield dan prcie earning ratio berpengaruh secara positif dan signifikan terhadap stock return. Puspitasari dan Linda (2013) melakukan penelitian sejenis 
mereka menemukan bahwa Perubahan dividend yield berpengaruh terhadap return saham. Friezkhaana (2013) menemukan bahwa price earning ratio, memiliki pengaruh signifikan terhadap return saham.

Berdasarkan uraian di atas, maka masalah yang dirumuskan dalam penelitian ini adah sebagai berikut : (1) Apakah terdapat pengaruh dividend yield terhadap reaksi investor pada perusahaan manufaktur yang terdaftar di Bursa Efek Indonesia ? (2) Apakah terdapat pengaruh price earning ratio terhadap reaksi investor pada perusahaan manufaktur yang terdaftar di Bursa Efek Indonesia?

\section{B. Tinjauan Pustaka dan Hipotesis}

\section{Return Saham}

Return saham menurut Tandelilin (2010) menyatakan bahwa: "Return merupakan salah satu faktor yang memotivasi investor berinvestasi dan juga merupakan imbalan atas keberanian investor menanggung resiko atas investasi yang dilakukannya". Sedangkan menurut Jogiyanto (2000) merupakan hasil yang diperoleh dari investasi.

Return dapat berupa return realisasi yang sudah terjadi maupun return ekspektasi yang belum terjadi namun diharapkan akan terjadi di masa mendatang. Return realisasi merupakan return yang sudah terjadi. Return realisasi dihitung berdasarkan data historis. Return ini penting karena digunakan sebagai salah satu pengukur kinerja perusahaan dan juga berguna sebagai dasar penentuan return ekspektasi dan resiko di masa datang.

Secara sistematis, rumus untuk menghitung return dari suatu sekuritas bisa dituliskan dalam persamaan : (Husnan, 2001)

$$
R_{i t}=\frac{\left(p_{i t}-P_{i t-1}\right)}{P_{i t-1}}
$$

Analisis statistik perhitungan returntersebuut tidak bias, karena terpengaruh oleh magnitude pembaginya, perhitungan return dilakukan dengan cara sebagai berikut :

$$
R_{i t}=\operatorname{Ln} \frac{P_{i t+1}}{P_{i t}}
$$

$\mathrm{R}_{\mathrm{it}}=$ return saham $\mathrm{i}$ untuk periode $\mathrm{t}$ (hari, bulan, tahun berjalan,dan sebagainya).

$\mathrm{P}_{\mathrm{it}+1}=$ harga saham penutupan i pada periode sebelumnya.

$\mathrm{P}_{\mathrm{it}}=$ harga saham penutupan i pada periode $\mathrm{t}$. 


\section{Dividend Yield dan Return}

Menurut Abdul Moin (2003), Dividend yield adalah perbandingan antara dividend per lembar saham dengan harga saham per lembar.

Dari pengertian di atas dapat disimpulkan bahwa dividend yield ini menunjukkan tingkat keuntungan yang dinikmati oleh pemegangsaham untuk setiap rupiah harga pasar saham.

Secara sistematis, rumus untuk menghitung dividendyield adalah sebagai berikut (Moin, 2003) :

Dividen Per lembar Saham

Harga Per lembar Saham

Dividend yield merupakan sebagian dari total return yang akan diperoleh investor. Biasanya perusahaan yang mempunyai prospek pertumbuhan tinggi akan mempunyai dividend yield yang rendah, karena dividend sebagian besar akan diinvestasikan kembali. Kemudian karena perusahaan dengan prospek yang tinggi akan mempunyai harga pasar saham yang tinggi, yang berarti pembagiaanya tinggi, maka dividend yield untuk perusahaan macam ini akan cendrung lebih rendah (Hanafi,2004).

Wagiri (2013) dan Ponsian, dkk (2015) Mereka mengatakan bahwa dividend yield berpengaruh negatif dan tidak signifikan terhadap harga saham. Hasil penelitian ini konsisten dengan Fernandus (2015) dan Arslan dan Zaman (2014), Mereka menyatakan bahwa dividend yield tidak berpengaruh positif terhadap harga saham. Berbeda dengan penelitian yang dilakukan oleh Puspitasari dan Linda (2013) dalam penelitiannya menyatakan bahwa Perubahan dividend yield berpengaruh terhadap return saham perusahaan. Awidia (2004) Dividend yield memiliki pengaruh positif dan signifikan terhadap return saham.

Berdasarkan uraian diatas, dapat dikembangkan hipotesis pertama sebagai berikut :

\section{H1: Dividend yield berpengaruh negatif dan signifikan terhadap reaksi investor pada perusahaan manufaktur yang terdaftar di Bursa Efek Indonesia.}

\section{Price Earning Ratio dan Return}

Menurut Tandelilin (2010) pengertian price earning ratio adalah ratio atau perbandingan antara harga saham terhadap earning perusahaan. Investor akan menghitung berapa kali nilai earning yang tercermin dalam harga suatu saham. Sedangkan menurut Jogiyanto (2008), price earning ratio menunjukkan rasio dari harga saham terhadap earning. Rasio ini menunjukkan berapa besar investor menilai harga dari saham terhadap kelipatan dari earning. 
Secara sistematis, rumus untuk menghitung price earning ratio adalah sebagai berikut (Tandelilin, 2010) :

$$
\text { PER }=\underline{\text { Harga per lembar saham }}
$$

Sulaiman dan Hadi (2004) menjelaskan bahwa price earning ratio digunakan oleh para investor untuk memprediksi kemampuan perusahaan dalam menghasilkan laba di masa yang akan datang. Perusahaan yang memiliki price earning ratio yang tinggi biasanya memiliki peluang tingkat pertumbuhan yang tinggi, begitu juga sebaliknya perusahaan yang memiliki price earning ratio yang rendah biasanya memiliki tingkat pertumbuhan yang rendah.

Meythi dan Mathilda (2012) menemukan bahwa price earning ratio memiliki pengaruh negatif dan signifikan terhadap return saham. Hasil penelitian ini konsisten dengan Emamgholipour, dkk (2013) dan Jatmiko (2015) Mereka menunjukkan bahwa price earning ratio berpengaruh negatif dan signifikan terhadap stock return. Namun berbeda dengan penelitian yang dilakukan oleh Margaretha dan irma (2008) menyimpulkan bahwa price earning ratio berpengaruh secara positif dan signifikan terhadap stock return.

Berdasarkan uraian diatas, dapat dikembangkan hipotesis pertama sebagai berikut :

\section{H2 : Price earning ratio berpengaruh negatif dan signifikan terhadap reaksi investor pada perusahaan manufaktur yang terdaftar di Bursa Efek Indonesia.}

\section{METODE PENELITIAN}

Pada metodologi penelitian menggunakan penelitian kuantitatif karena penelitian ini bersifat menganalisa lebih lanjut laporan keuangan perusahaan manufaktur subsektor makanan dan minuman yang go publicdi BEI dan menafsirkan hasilnya dalam bentuk angka-angka. Variabel independen dalam penelitian ini adalah dividend yield dan price earning ratio sedangkan variabel dependen adalah return saham.

\section{Populasi dan Sampel}

Perusahaan manufaktur subsektor makanan dan minuman yang go public dijadikan sebagai objek dalam penelitian karena perusahaan ini memiliki peranan penting dalam pertumbuhan ekonomi di Indonesia. Sehingga dijadikan prioritas pemerintah dalam mendorong industri sebagai penggerak ekonomi nasional. 
Populasi yang digunakan dalam penelitian ini adalah Perusahaan Manufaktur Subsektor Makanan dan Minuman yang terdatar di Bursa Efek Indonesia (BEI) selama periode 2011-2015 yaitu sebanyak 14 Perusahaan .

Penelitian ini mengambil sampel perusahaan manufaktur yang terdaftar di BEI pada tahun 2011-2015 yang diambil dengan mengunakan metode purposive sampling, dimana penelitian ini tidak dilakukan pada seluruh populasi, tetapi terfokus pada target dengan mempertimbangkan kriteria-kriteria tertentu yang telah dibuat terhadap objek yang sesuai dengan tujuan penelitian. Kriteria pemilihan sampel adalah sebagai berikut : (1) Perusahaan yang terdaftar di BEI tahun 20112015. (2) Perusahaan yang bergerak dalam bidang manufaktur. (3) Perusahaan yang memiliki laporan keuangan lengkap. (4) Perusahaan yang tidak melakukan coorporate action selama periode pengamatan, selain pembagian deviden.

Setelah dilakukan analisis, maka penulis menenetapkan 7 perusahaan yang layak dijadikan sebagai sampel penelitian, yaitu : (1) Delta Djakarta Tbk. (2) Indofood CBP Sukses Makmur Tbk. (3) Indofood Sukses Makmur Tbk. (4) Multi Bintang Indonesia Tbk. (5) Mayora Indah Tbk. (6) Nippon Indosari Corpindo Tbk. (7) Sektar Laut Tbk.

Definisi Operasional Variabel Penelitian

\begin{tabular}{|l|c|c|c|}
\hline No & Variabel & Definisi & Pengukuran \\
\hline 1 & $\begin{array}{c}\text { Return } \\
\text { Saham }\end{array}$ & $\begin{array}{c}\text { Merupakan logaritma natural } \\
\text { dari perbandingan harga } \\
\text { saham perioda berikutnya } \\
\text { dengan perioda saat ini }{ }_{i t} .\end{array}$ & $R_{i t}=\operatorname{Ln} \frac{P_{i t+1}}{P_{i t}}$ \\
\hline 2 & Dividend $^{\text {Yield }}$ & $\begin{array}{c}\text { Merupakan perbandingan } \\
\text { dividen per lembar saham } \\
\text { dengan harga per lembar } \\
\text { saham. }\end{array}$ & DY $=\frac{\text { Dividen Per lembar Saham }}{\text { Harga Per lembar Saham }}$ \\
\hline 3 & Price & $\begin{array}{c}\text { Merupakan perbandingan } \\
\text { harga pasar dengan laba per } \\
\text { lembar saham. }\end{array}$ & PER $=\frac{\text { Harga Per lembar Saham }}{\text { Laba per lembar Saham }}$ \\
\hline
\end{tabular}

Sumber : Husnan (2001) ; Moin (2003) \& Tandelilin (2010)

\section{Model dan Analisis Penelitian}

Rumus persamaan uji regresi berganda adalah sebagai berikut :

$$
R i t=\alpha+\beta_{1} D Y_{i t}+\beta_{2} P E R_{i t}+e
$$


Berdasarkan model ini, dijelaskan bahwa Rit merupakan return saham individual pada periode $\mathrm{t}$; DYit merupakan dividend yield pada periode t; PERit merupakan price earning ratio pada periode $\mathrm{t}, \alpha$ merupakan konstanta ; $\beta$ merupakan koefisien regresi (nilai peningkatan ataupun penurunan) ; $e$ merupakan Nilai Residual (Faktor Penggangu).

\section{HASIL DAN PEMBAHASAN}

Berikut hasil pengolahan data penelitian :

1. Analisis Statistika Deskriptif

Analisis statistika deskriptif mencakup nilai jumlah sampel $(\mathrm{N})$, rata-rata sampel (mean), nilai maksimum, nilai minimum serta standar deviasi $(\sigma)$ untuk masing-masing variabel.

Tabel 1

Statistika Deskriptif

\begin{tabular}{|l|c|c|c|c|c|}
\hline \multicolumn{1}{|c|}{ Variabel } & N & Maksimum & Minimun & Mean & $\begin{array}{c}\text { Standar } \\
\text { Deviasi }\end{array}$ \\
\hline Dividend Yield & 35 & 0.1000 & 0.0000 & 0.0226 & 0.0221 \\
\hline Price Earning Ratio & 35 & 56.1700 & 5.8800 & 23.1907 & 11.3076 \\
\hline Return Saham & 35 & 0.7300 & -0.8400 & 0.1320 & 0.3751 \\
\hline
\end{tabular}

Sumber : Data diolah

Pada tabel di atas menunjukan bahwa jumlah data yang digunakan dalam penelitian ini sebannyak 35 sampel data yang diambil dari laporan tahunan publikasi sektor manufakfur subsektor perusahaan makanan dan minuman yang tercatai di BEI periode 2011-2015. Data rasio dividend yield tertinggi (maksimum) adalah 0.1000 dan yang terendah (minimun) adalah 0.0000, kemudian rata-rata dividend yield sebesar 0.0226 dengan deviasi sebesar 0.0221. Data rasio price earning ratio tertinggi (maksimum) adalah 56.1700 dan yang terendah (minimun) adalah 5.8800, kemudian rata-rata price earning ratio sebesar 23.1907. Sementara standar deviasi sebesar 11.3076. Data return saham mempunyai tertinggi (maksimum) adalah 0.7300 dan yang terendah (minimun) adalah -0.8400, kemudian rata-rata 0.1320 dengan nilai standar deviasi sebesar 0.3751 .

\section{Analisis Regresi Berganda}

Alat analisis yang digunakan dalam penelitian ini adalah analisis regresi linear berganda. Sebelum model regresi di estimasi dari regresi dilakukan, maka penulis telah melakukan teknik analisis data pada penelitian ini dengan menggunakan uji asumsi klasik yang tediri dari uji normalitas, uji multikolinearitas, uji heteroskedastitas, dan uji korelasi. 
Melalui hasil pengujian normalitas, pengujian multikolinearitas, pengujian heteroskedastitas, dan pengujian korelasi, disimpulkan bahwa seluruh data variabel dalam penelitian ini (dividend yield, price earning ratio, dan return saham) telah memenuhi asusmsi teori pengujian yang telah ada. Oleh karena itu, langkah selanjutnya untuk mencapai tujuan penelitian untuk memberikan hasil regresi dengan menggunakan estimasi data panel untuk hipotesis yang telah dikembangkan sebelumnya.

Tabel 2

Hasil Uji Regresi Linear Berganda

\begin{tabular}{lrlll}
\hline \hline \multicolumn{1}{c}{ Variable } & Coefficient & Std. Error & t-Statistic & Prob. \\
\hline \hline \multicolumn{1}{c}{ C } & 0.554319 & 0.239123 & 2.318133 & 0.0270 \\
DY & -0.094202 & 0.173822 & -0.541945 & 0.5916 \\
PER & -0.015077 & 0.005955 & -2.532009 & 0.0164 \\
\hline \hline R-squared & 0.176373 & Mean dependent var & 0.132000 \\
Adjusted R-squared & 0.124896 & S.D. dependent var & 0.375098 \\
S.E. of regression & 0.350893 & Akaike info criterion & 0.825147 \\
Sum squared resid & 3.940034 & Schwarz criterion & 0.958462 \\
Log likelihood & -11.44007 & Hannan-Quinn criter. & 0.871167 \\
F-statistic & 3.426271 & Durbin-Watson stat & 1.806339 \\
Prob(F-statistic) & 0.044842 & & & \\
\hline
\end{tabular}

Sumber : Eviews

Dari Tabel 2 dihasilkan nilai koefisien regresi untuk variabel Dividend Yield sebesar -0.094202 bertanda negatif dengan nilai probabilitas $0.5916>0.05$ yang berarti bahwa Dividend Yield mempunyai pengaruh positif yang tidak signifikan terhadap Return Saham. Dengan demikian dapat disimpulkan hipotesis pertama ditolak.

Penelitian ini konsisten dengan hasil penelitian yang dilakukan oleh wagiri (2013) dia menyatakan bahwa dividend yield berengaruh negatif dan tidak signifikan terhadap harga saham perusahaan sektor aneka industri periode 20012011. Hal ini mengidendikasikan bahwa Hubungan yang negatif antara dividend yield dan return saham menunjukan apabila terjadi peningkatan pada nilai dividend yield perusahaan maka return saham mengalami penurunan. 
Arslan dan Zaman (2014), mereka menyatakan bahwa dividend yield berpengaruh negatif terhadap stock prices. Ponsian, dkk (2015) dan Fernandus (2015) Mereka menyatakan bahwa dividend yield berpengaruh negatif dan tidak signifikan terhadap share price. Sejalan dengan penelitian ini, Puspitasari dan linda (2013), mereka menyatakan bahwa perubahan dividend yield secara simultan tidak berpengaruh terhadap return saham perusahaan manufaktur yang terdaftar pada Bursa Efek Indonesia.

Dari Tabel 2 juga menunjukkan hasil nilai koefisien regresi untuk variabel Price Earning Ratio sebesar -0.015077 bertanda negatif dengan nilai probabilitas 0.0164 $<0.05$ yang berarti bahwa Price Earning Ratio mempunyai pengaruh negatif yang signifikan terhadap Return Saham. Dengan demikian dapat disimpulkan hipotesis kedua ditolak.

Hasil penelitian ini konsisten dengan penelitian yang dilakukan oleh Mathilda (2012) dalam penelitiannya yang berjudul Pengaruh Price Earninng Ratio dan Price To Book Value Terhadap Return Saham Indeks LQ 45 menyatakan bahwa price earninng ratio berpengaruh negatif dan signifikan terhadap return saham. Hubungan yang negatif antara price earninng ratio dan return saham menunjukan apabila terjadi peningkatan pada nilai price earninng ratio perusahaan maka return saham mengalami penurunan.

Hasil ini diperkuat oleh Emamgholipour, dkk (2013), Mereka mengatakan bahwa price earninng ratio berpengaruh negatif dan signifikan terhadap return saham. Sejalan dengan penelitian ini, Jatmiko (2015), Dia mengatakan bahwa price earninng ratio berpengaruh negatif dengan return.

\section{E. PENUTUP}

\section{KESIMPULAN}

Tujuan uatama dari penelitian ini adalah untuk menguji pengaruh dividend yield dan price earning ratio terhadap reaksi investor yang di proxy dengan menggunakan return saham pada perusahaan manufaktur yang terdaftar di Bursa Efek Indonesia.

Berdasarkan hasil pengujian dan analisis data mengenai pengaruh dividend yield dan price earning ratio terhadap return saham dengan menggunakan analisis regresi linear berganda, dapat disimpulkan bahwa dividend yield menunjukan nilai koefisien negatif yaitu sebesar -0.094202 dengan tingkat probabilitas lebih dari 0.05 yaitu sebesar 0.5916. Untuk price earning ratio juga menunjukan nilai koefisien negatif yaitu sebesar -0.094202 dengan tingkat probabilitas kurang dari 0.05 yaitu 0.0164 .

Berdasarkan hal tersebut dapat disimpulkan bahwa dividend yield berpengaruh negatif dan tidak signifikan terhadap return saham. Sedangkan untuk price earning ratio berpengaruh negatif dan signifikan terhadap return saham. 


\section{SARAN}

Berdasarkan hasil dari penelitian dan kesimpulan di atas diharapkan melakukan penelitian lanjutan dengan memperbanyak jumlah observasi agar memperoleh hasil yang lebih akurat misalnya : periode di perpanjang, data dalam bulanan, sektor perusahaan diperluas dengan unit analisis dan sampel yang berbeda, menambahkan variabel indenpenden lain serta menggunakan periode pengamanan yang lebih panjang agar diperoleh kesimpulan yang mendukung teori dan konsep diterima secara umum.

\section{DAFTAR PUSTAKA}

Andriza, R., \& Yusra, I. (2019). Pengaruh kepemilikan manajerial dan kebijakan deviden terhadap kemakmuran Investor dan nilai perusahaan yang tercatat pada indeks LQ45. INA-Rxiv.

Arslan, Muhammad \& Zaman, Rashid (2014). Impact Of Dividend Yield and Price Earning Ratio On Stock Return : A Study Non-Financial Listed Firms Of Pakistan. Journal of Finance and Accounting. VOL. 5. No. 19

Darmadji, Tjiptono. (2008). Pasar Modal di Indonesia, Pendekatan Tanya Jawab, cetakan ketiga, Penerbit : Salemba Empat, Jakarta

Emamgholipour, Milad, \& Pouraghajan, Abbasali, \& Tabari, Naser Ail Yadollahzadeh, \& Haghparast, Milat, \& Shirsavar, Ali Akbar Alizadeh. (2013). The Effects Of Performance Evaluation Market Ratios On The Stock Rerturn : EVidence From The Tehran Stock Exchange. International Research Journal of Aplied and Basic Sciences. Vol, 4 (3) : 696-703

Fun, Liem Pei \& Basana, Sautma Ronni. (2012). Price Earning Ratio and Return Analysis (Evidence from Liquidity 45 Stocks Listed in Indonesia Stock Exchange). Jurnal manajemen dan Kewirausaaan, Vol 14, No. 1, Maret 2012 : 7-12

Gujarati, D. N. (2003). Basic Econometrics. 4th edition. McGraw-Hill International Edition, Economics Series.

Imam Ghozali. (2005). Analisis Multivariate dengan program SPSS. Semarang; Badan Penerbit Universitas Diponegoro.

Jatmiko, Dadang Prasetyo. (2015). The Relationship Between Return, Price Earning Ratio, Price To Book Value Ratio, Size and Beta in Different Data Period. Investment management and financial innovations, volume 12, issue 1, 2015

Jogiyanto, H.M. (2010). Teori Portofolio dan Analisis Investasi. Edisi Ketujuh. BPFE. Yogyakarta.

Margaretha, Farah \& Damayanti, Irma. (2008) “ Pengaruh price Earning Ratio, Divident Yield, dan Market to Book Ratio Terhadap Stock Return di Bursa 
Efek Indonesia. Jurnal Bisnis dan Akuntansi. Vol : 10, No.3 Desember 2008, Hlm 149-160

Martha, L., Sogiroh, N. U., Magdalena, M., \& Susanti, F. (2018). Profitabilitas dan Kebijakan Dividen terhadap Nilai Perusahaan. Jurnal Benefita, 3(2), 227238.

Meythi \& Mathilda, Mariana. (2012). Pengaruh Price Earninng Ratio dan Price To Book Value terhadap Return Saham Indeks LQ 45 (Perioda 2007-2009). Jurnal Akuntansi, Volume 4, Nomor 1, Mei 2012, hal. 1-21

Puspitasari, Anggraeni \& Purnamasari, Linda. (2013). Pengaruh Perubahan Dividend Payout Ratio Dan Dividend Yield Terhadap Return Saham (Studi Pada Perusahaan Manufaktur Di Bursa Efek Indonesia. Journal of Business and Banking. Volume 3, No. 2, November 2013, pagrs 213-222

Putra, A. D., \& Yusra, I. (2019). Peran profitabilitas dalam memoderasi pengaruh free cash flow terhadap kebijakan dividen di Indonesia. INA-Rxiv.

Sari, N. N., \& Yusra, I. (2018). Analisis Likuiditas, Leverage dan Kebijakan Dividen berdasarkan Siklus Hidup Perusahaan pada Saham LQ45. INA-Rxiv.

Sigalingging, Y. N., \& Dewi, A. S. (2019). Pengaruh Kebijakan Dividen dan Ukuran Perusahaan terhadap Leverage Perusahaan dengan Investment Opportunity Set (IOS) Sebagai Variabel Moderasi pada Sektor Trades, Services \& Investment yang Terdaftar di BEI. INA-Rxiv, 1-23.

Sugiyono. (2012). Metode Penelitian Kuantitatif Kualitatif dan $R \& B$. Bandung : Alfabeta.

Tandelilin, Eduardus. 2010. Portofolio dan Investasi Teori dan Aplikasi. Edisi pertama. Yogyakarta : BFE Yogyakarta.

Yusra, I. (2014). Pengaruh pengumuman perubahan peringkat obligasi terhadap perilaku investor pada perusahaan asing dan domestik. Jurnal Riset Manajemen Dan Akuntansi, 1(1).

Yusra, I. (2014). Analisis Return dan Likuiditas Saham Sebelum dan Sesudah Pengumuman Right Issue di Bursa Efek Indonesia. Jurnal Riset Manajemen Dan Akuntansi, 1(2), 150-163.

Yusra, I., Hadya, R., \& Fatmasari, R. (2019). The Effect of Retained Earnings on Dividend Policy from the Perspective of Life Cycle. Advances in Social Science, Education and Humanities Research, 203(Iclick 2018), 216-220.

Yusra, I., Herman, L. A., \& Begawati, N. (2018). Model kebijakan dividen berdasarkan siklus hidup perusahaan : studi empiris di indonesia. Jurnal Benefita, 3(2), 263-276. 